\title{
Evaluation of Potential Fair Trade Standards for an Ethical 3-D Printing Filament
}

\author{
S. R. Feeley ${ }^{1}$, B. Wijnen ${ }^{2} \&$ J. M. Pearce ${ }^{2,3}$ \\ ${ }^{1}$ Department of Biosystems \& Agricultural Engineering, Michigan State University, East Lansing MI, USA \\ ${ }^{2}$ Department of Materials Science \& Engineering, Michigan Technological University, Houghton MI, USA \\ ${ }^{3}$ Department of Electrical \& Computer Engineering, Michigan Technological University, Houghton MI, USA \\ Correspondence: Joshua Pearce, 601 M\&M Building, 1400 Townsend Drive, Houghton, MI 49931-1295, USA. \\ Tel: 1-906-487-1466. E-mail: pearce@mtu.edu
}

Received: November 27, 2014 Accepted: July 3, 2014 Online Published: September 14, 2014

doi:10.5539/jsd.v7n5p1 URL: http://dx.doi.org/10.5539/jsd.v7n5p1

\begin{abstract}
Following the rapid rise of distributed additive manufacturing with 3-D printing has come the technical development of filament extruders and recyclebots, which can turn both virgin polymer pellets and post-consumer shredded plastic into 3-D filament. Similar to the solutions proposed for other forms of ethical manufacturing, it is possible to consider a form of ethical 3-D printer filament distribution being developed. There is a market opportunity for producing this ethical 3-D printer filament, which is addressed in this paper by developing an "ethical product standard" for 3-D filament based upon a combination of existing fair-trade standards and technical and life cycle analysis of recycled filament production and 3-D printing manufacturing. These standards apply to businesses that can enable the economic development of waste pickers and include i) minimum pricing, ii) fair trade premium, iii) labor standards, iv) environmental and technical standards, v) health and safety standards, and vi) social standards including those that cover discrimination, harassment, freedom of association, collective bargaining and discipline.
\end{abstract}

Keywords: 3-D printing, filament, ethical product standards, fair trade standards, distributed manufacturing

\section{Introduction}

Recent developments in additive manufacturing, or 3-D printing, have made distributed manufacturing of high-value products for household use in any country in the world technically viable (Pearce, et al., 2010). In addition, recent work has shown home-based 3-D printing is economically attractive, enabling individuals to fabricate an exponentially growing list of free and open-source designs of products to meet their own needs (Wittbrodt, et al., 2013). Preliminary analysis also indicates distributed manufacturing with 3-D printing could reduce the environmental impact attributed to manufacturing household goods primarily by reducing transportation related embodied energy, but also by reducing the quantity of material used (Kreiger, et al., 2013; Kreiger and Pearce, 2013a). Recent sales figures in the developed world indicate that personalized or desktop manufacturing with 3-D printers is a growing trend (Economist, 2012; Blua, 2013; Make, 2013). A wide range of products can be produced by these low-cost desktop 3-D printers (Wittbrodt, et al., 2013; Martens et al., 2011). Open-source self-replicating rapid prototypers (or RepRaps) enable particularly fast scaling of 3-D printing technology to reach communities in the developing world (Pearce, et al., 2010), because RepRaps can manufacture over $50 \%$ of their own components (excluding fasteners). RepRaps are a low cost and easily repairable 3-D printer that can be used for both self upgrades, reprodution and fabricating replacement parts for low costs (Jones, et al., 2011). The cost of the printers themselves has already been shown to be an economically advantageous investment for scientific laboratories, schools and now middle-class households (Pearce, 2012; 2014; Anzalone, et al, 2013; Zhang, et al., 2013; Wittbrodt, et al., 2013). This economic feasibility exists despite highly marked-up costs of commercial 3-D printing filament (Baecheler, et al. 2013). However, if there is the potential to change the way products are manufactured following this distributed model, the same issues that arise for the ethical manufacturing of other products arises for the manufacturing of the raw material or 3-D printing filament (Litvinoff \& Madeley, 2007; McMurtry, 2009; Baradaran \& Barclay, 2011; Marcovitz, 2011; Bacon, 2005; Raynolds \& Ngcwangu, 2010; Nicholls \& Opal, 2004; Becchetti, 2008; Shreck, 2005; Valkila \& Nygren, 2010; Low \& Davenport, 2005; McDonagh, 2002; Adriani \& Becchetti, 2002; Ehrenberg, 1995; 
Hilowitz, 1997; Jaffee, 2007). Similar to the solutions proposed for other forms of ethical manufacturing, it is possible to consider a form of ethical 3-D printer filament distribution being developed.

There is a market opportunity for producing this ethical filament in the developing world, which has been created by five converging trends:

1) The market for pro-sumer fused filament 3-D printers (also called desktop 3-D printers or personal 3-D printers) continues to expand so rapidly that the dozens of SMEs providing low-cost printers are not able to meet demand (Economist, 2012; Blua, 2013; Make, 2013).

2) The rate of growth of open-source designs, presently numbering over 380,000 on a single design repository (Thingiverse, 2014), is expanding exponentially. As each new design has value that all 3-D printer users could potentially extract by investing in the time and materials to print the object, the greater and expanding catalog of objects is making 3-D printers increasingly attractive to consumers, a trend that will presumably accelerate trend as more users participate as shown in (1) (Wittbrodt, et al., 2013).

3) Commercial filament from $\$ 18.96 / \mathrm{kg}$ to $\$ 175.20 / \mathrm{kg}$ (3Ders, 2013). These costs are the primary impediment to accelerating (1) further. Yet these costs are not necessary, as 3-D printing filament is being sold for 20 times to 200 times above the cost of raw plastic $(\$ 1-4 / \mathrm{kg}$ ) (Alibaba, 2013). Even the cost of raw plastic is considerable compared to what could be done with recycled waste plastic filament. The commercial filament cost is now 500 times the energy costs of recycling filament (Kreiger, et al., 2013; Kreiger et al., 2014).

4) A number of designs for filament extruders and recyclebots (waste polymer desktop extruders) have been developed, which can produce useable filament from recycled post-consumer plastic including open-source tools using the recyclebot name, Filabot, Filstruder and Lyman Extruder (Baecheler, et al. 2013; Kreiger and Pearce, 2013; Kreiger et al., 2014; Filabot, 2012; Lyman, 2012; Elmore, 2013; Thompson, 2012; Douglass, 2013). In addition, there are now a number of commercial or pre-commercial (e.g. Kickstarter) filament extruder systems such as EWE in Italy (EWE Industries, 2014) and Strooder in the U.K. (Omni Dynamics, 2014).

5) There is a growing concern (due to climate destabilization and ecological system deterioration) and interest among consumers for low-carbon, environmentally sustainable and ethically produced and distributed products (Brenton, Edwards-Jones \& Jensen, 2009; Sahota, et al., 2008; Loureiro, McCluskey \& Mittelhammer, 2001).

This paper addresses this need and market opportunity by developing an "ethical product standard" for 3-D printing filament based upon a combination of existing fair-trade standards, life cycle analysis of the embodied energy and emissions from recycled filament production and 3-D printing manufacturing, and consultation with partners and stakeholders.

\section{Developing World Non-ethical and Ethical Filament Models}

Currently 3-D printer filament is generally mass manufactured and distributed like any other product using raw virgin materials, which are eventually discarded as seen in Figure 1. As can be seen in Figure 1, the plastic is processed from oil (although it should be noted some time natural gas or bio-based feedstocks are used), turned into pellets and then pushed through commercial scaled extruders. When the filament is completed it is packaged and shipped after being marketed to a consumers all over the globe. After printing this filament is presumably trashed following the standard model of consumer good and most likely ends the material life after being transported to a landfill. The RepRap (and various commercial clones and derivatives) extruder intakes a filament of the working material (acrylonitrile-butadiene-styrene [ABS], Polylactic acid [PLA] polymers, most commonly and high density polyethelene [HDPE], low density poly-ethylene [LDPE], polycarbonate [PC], polystyrene [PS], high impact polystyrene [HIPS], polyphenylsulfone [PPSF or PPSU], polyetherimide [PEI], polyamide $[\mathrm{PA}]$, polypropylene $[\mathrm{PP}]$, polyoxymethylene $[\mathrm{POM}]$, and composites and other plastics less commonly), heats it, and extrudes it through a nozzle where it deposits a 2-D layer of the working material, then the $\mathrm{Z}$ (vertical) axis will raise, and the extruder will deposit another layer on top of the first and repeat this process to build a 3-D object. The ecological impact of printing with these materials is often better than conventional manufacturing (Kreiger and Pearce, 2013a; 2013b), however, there are significant reductions in environmental impact using recycled materials to produce filament in all cases (Kreiger, et al., 2013; Kreiger et al., 2014). These improvements are further magnified if desktop filament recyclers or recyclebots are used (Baecheler, et al. 2013; Kreiger, et al., 2013; Kreiger et al., 2014). The Perpetual Plastic Project (2014), which provides recycling installations for education and outreach, has already demonstrated the viability of recycling PLA, PS, LDPE, PA and PP (Bleijerveld, 2014). This production process for ethical filament using such a process is shown in Figure 2. 


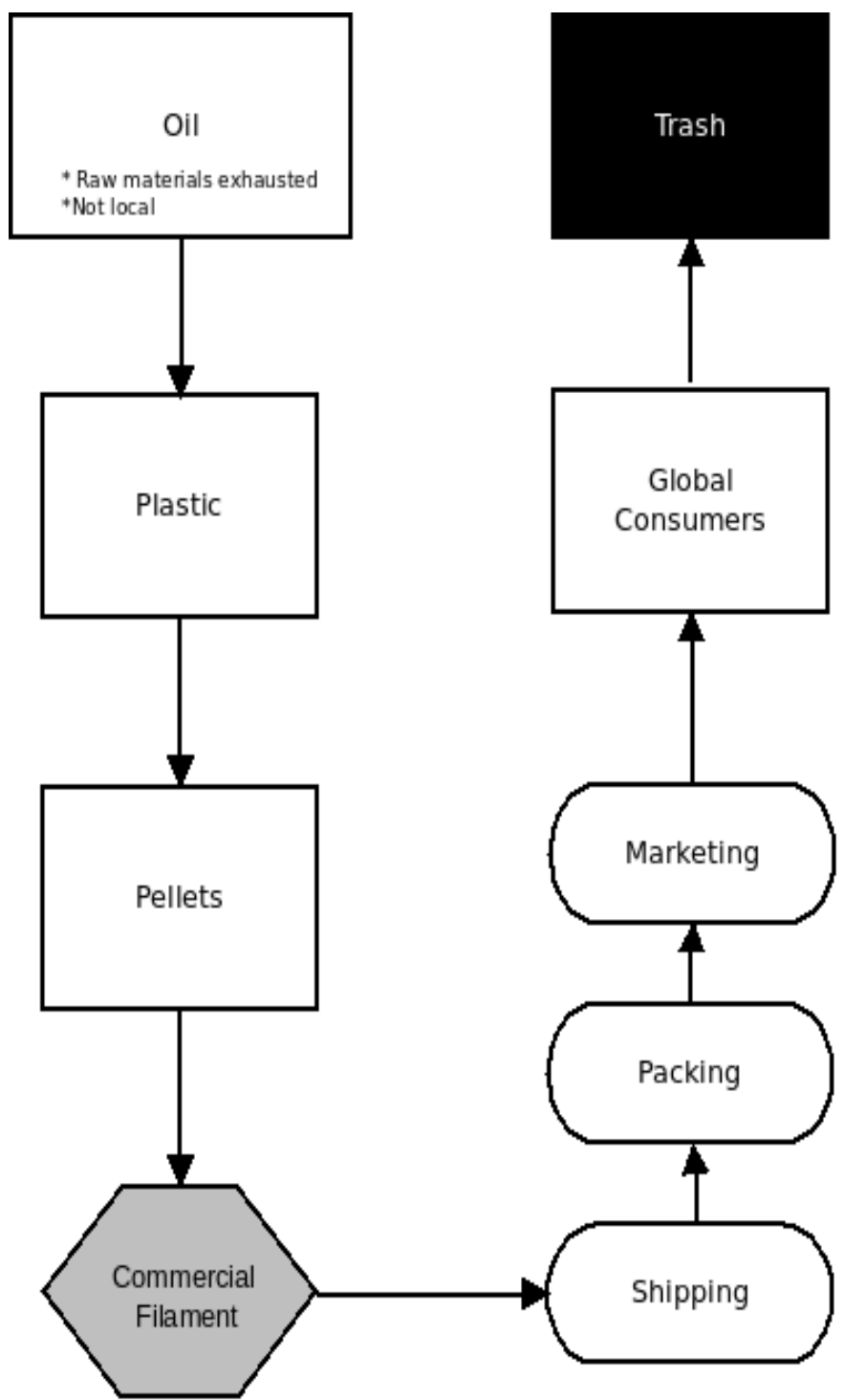

Figure 1. Conventional method of commercial filament production, distribution and disposal 


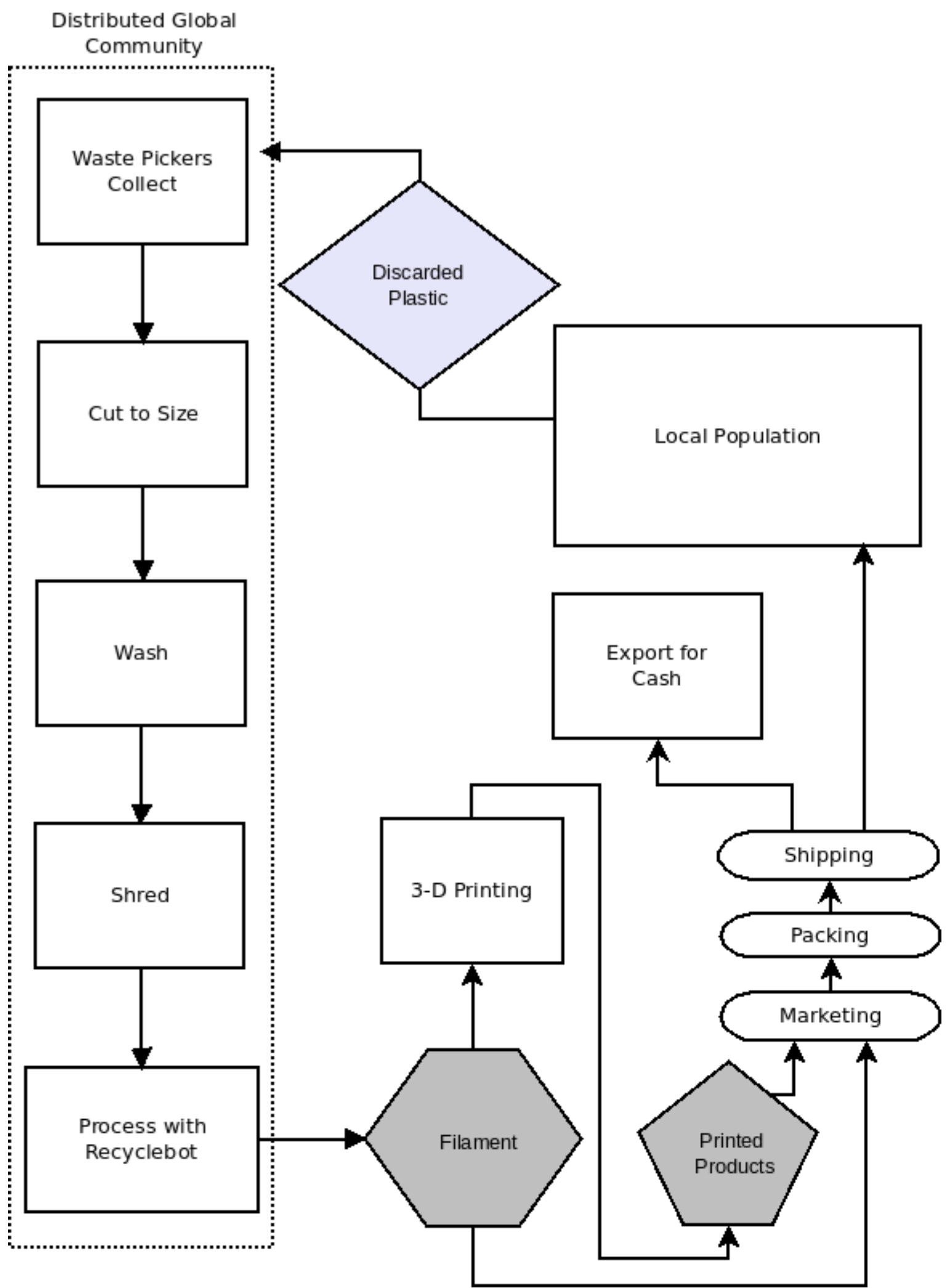

Figure 2. Production, distribution and recycling of ethical filament

As can be seen in Figure 2, post-consumer plastic is first collected by waste pickers working in landfills. This plastic can be processed by the same waste pickers, which involves cutting into component pieces that can be fit into a shredder or flaker and be washed to remove waste and food residue. The following step can also be 
completed by a waste picker or a dedicated machine operator - run the polymer flakes or shreds through a form of recyclebot including adding pigmentation and possibly additives to get specific properties. For example, there are already functional 3-D printer filaments on the market such as glow in the dark and electrically conductive filaments. Next the filament must undergo appropriate quality control. This is primarily going to be limited to simple printability tests or density, diameter and cross-section shape tests, but could also include more detailed chemical verification, contaminant chemical analysis, and melting temperature, Then the filament can be packaged and shipped to customers either locally or in the global system. Finally, in addition to selling the filament itself as a product, it can be used as a feedstock to print higher value items with a RepRap or similar 3 -D printer. As has been shown previously, these objects can be highly customized and of very high value (e.g. several dollars of plastic can replace several hundred dollars of custom orthotics) (Wittbrodt, et al., 2013). These higher value products can be either marketed to the local population to meet their needs and desires or exported for cash. At the end of the products life cycle if it has gone to the export market and the most likely end of life is again another land fill. However, if the plastic product is used in a community with an existing polymer to 3-D printer filament infrastructure in place the discarded plastic can go directly back into the loop of recycling. The current challenge with closing the loop is that the vast majority of the plastic from printed products is difficult to verify. Future work is needed to develop ether open-source hardware for low-cost chemical testing or policies/open source software that encourage 3-D printer users to print in recycling codes on their products (the same way conventional products made from plastic are labeled).

As seen in Figure 2, recyclers (waster pickers) are an integral part for the raw material collection for an ethical filament value chain. Waste pickers are already common in many regions of the developing world. Scavenging at dumps occurs in cities throughout the economically developing world including Manila, Mexico City, Cape Town, Bangalore, Guadelajara, Rio de Janeiro, Dar es Salaam, Guatemala City and many others (Bernache, 2003). Over 20,000 women work as paper pickers in Ahmedabad, the largest city in the Indian state of Gujarat (Salahuddin \& Shamim, 1992). Up to 150,000 waste pickers are estimated to be active in the Municipal Corporation of Delhi area (Chaturvedi, 1998). And it is reported that up to 2\% of the population in Asian and Latin American cities depend on waste picking to earn their livelihood (Medina, 2000). In general, waste pickers are marginalized segment of the urban population within the developing world that earn a living sifting through trash in order to sell recyclables. Waste pickers can do bulk recyclable materials, but are often targeting higher-value products than waste plastic containers. An ethical filament ecosystem would enable waste pickers to create a new higher value product (3-D filament) from a waste stream they utilize sparingly with a relatively modest capital investment in an owned (or collectively owned), leased, or rented recyclebot. Again, it is possible that this filament could be used to print even higher-value products for sale locally or to the global community as shown in Figure 2. Waste picking is a tiring and physically demanding occupation that provides meager income and little opportunity for advancement, but the majority of waste pickers has no alternative. In order to ensure that the waste pickers/recyclers are not abused the following fair-trade standards for ethical 3-D filament are proposed based on standards meant to protect other at-risk workers.

\section{Proposed Fair Trade Standards for Filament}

A main goal of fair trade is to provide opportunities and stable trading partners to economically disadvantaged producers and to open up new markets (WFTO, 2013). Fair trade ethical filament has the possibility of creating many jobs without a large startup cost or difficult job training. People can be employed to collect and process the plastic through all the steps shown in Figure 2. They can sell the plastic or if they had a RecyleBot, they could turn it into filament themselves to provide a higher value and more income. This filament could then be sold to make useful products that could be in turn sold. In addition, a worker could buy or build a RepRap 3-D printer and begin making finished products from the waste plastic filament. These finished products can have substantial value (Wittbrodt, et al., 2013) and can either be used to offset household costs or again sold on the market for profit. This process could be especially beneficial in rural areas where markets are not as varied as in cities and consumers simply lack access to many products.

The standard adopts a similar approach to other fair trade standards in the requirements are broken down between minimum requirements to be considered for 'ethical filament' accreditation and additional requirements based on progress towards desirable goals to be worked towards as the industry matures. These standards include i) minimum pricing, ii) the potential for and the application of a fair trade premium, iii) labor standards, iv) environmental standards, v) health and safety standards, and vi) social standards including those that cover discrimination, harassment, freedom of association, collective bargaining and discipline. 


\subsection{Minimum Price}

A fair minimum price must be paid to the producers to insure that waste pickers' wages either meet or exceed sector regulations, collective bargaining agreements, and regional average minimum wage. Minimum wages are generally set by country. In countries where there is no legal minimum wage, organizations should use benchmarking against comparable businesses and jobs with similar skill sets to determine the correct level of payment. Payment should exceed or match minimum wages for similar occupations (Fair Trade USA, 2013; FLA, 2013; Fairtrade Foundation, 2013). The collecting of plastic for recycled filament might be comparable to pickers of tea, coffee, cotton or cocoa.

Having a minimum price also ensures the funds necessary to maintain a sustainable business are available. If the minimum price is lower than the market price, the market price prevails (Fair Trade USA, 2013; WFTO, 2013; FLA, 2013; Fairtrade Foundation, 2013a). Currently, the market price for 3-D printer filament greatly exceeds the theoretical cost of waste picker filament creation even if the waste pickers earn U.S. minimum wages because of the high margins currently earned by 3-D filament suppliers. For example, a recyclebot can produce $1 \mathrm{~kg}$ of printable HDPE filament from 20 discarded milk jugs uses only US $\$ 0.10$ of electricity and minimal operator time to complete the tasks on the left side of Figure 2, which would allow waste pickers to participate in other economic activities (e.g. recycle other materials) while the recyclebot spools filament. This cost differential may not always exist as competition from both conventional filament suppliers improves and recycled filament pushes the competitive market price of 3-D printer filament even lower.

\subsection{Fair Trade Premium}

Once the current cost differential between commercial filament and waste-picker recycled filament erodes, a premium price could be instituted, which would make the filament more expensive (similar to Fair Trade Coffee). The extra money is called the Fair Trade Premium. This premium is to be invested in projects for social, economic, and environmental development. The premium is fixed by the FLO Standards Unit in the same way as the minimum price and remains the same, even if the producer is paid more than the minimum price for the product (Fairtrade Foundation, 2013a). A Joint Body is developed, which includes workers and management and decides how the premium is to be spent (Fairtrade Foundation, 2013b). In other sectors the premium fund is typically invested in education and health care, farm improvements to increase yield and quality, or processing facilities to increase income (Fairtrade Foundation, 2013a). In this case it could be spent for further development of the open-source recyclebot technology to benefit all the small businesses using the technology. The money can also be used for projects like fixing roads, creating public recreation spaces, providing scholarships and improving access to clean water for the communities participating (Fair Trade Certified, 2013).

\subsection{Labor Standards}

No child labor is to be used. Child labor is defined by the International Labor Organization (ILO) as work that is physically, socially or morally damaging to children, or interferes with their attendance of school (ILO, 2013). The Fair Labor Association (FLA) states no one under the age of 15 or the age of compulsory education, whichever is higher, is to be employed (FLA, 2013). In the context of recycled filament, children could work finding, sorting, and cleaning plastic outside of school hours and during school holidays. This would be considered a positive experience as long as it does not affect their health and personal development or interfere with their schooling. This kind of work contributes to children's development and to the welfare of their families; provides them with skills and experience, and helps to prepare them to be productive members of society during their adult life (ILO, 2013).

The regular work week of a full time worker is not to exceed 48 hours and the regular work week plus over time is not to exceed 60 hours (FLA, 2013). Overtime is to be paid at a premium rate. No forced or compulsory labor of any kind is to be used including prison labor, indentured labor, or bonded labor. Workers must receive compensation for their work, so no unpaid internships are permissible. Waste picker, recyclebot and 3-D printer operator compensation should be at least the minimum wage or the appropriate prevailing wage, whichever is higher. Migrant, temporary, seasonal, and subcontracted workers are to be paid on a basis of equal pay for equal work performed. Labor standards are to be followed as stated by the Fair Labor Association (FLA, 2013).

\subsection{Environmental Standards}

Environmentally conscious actions are to be taken whenever possible with the goal of reducing green house gas admissions and energy consumption. Creating recyclebot filament has already been shown to be environmentally beneficial (Kreiger, et al., 2013; Kreiger et al., 2014). Further work could improve the insulation on the recyclebots to improve their efficiency among more technical and complicated improvements such as the 
optimization of the extruder design for different types of waste plastic. Measures should be taken to offset negative impacts that the workplace has on the environment (Fair Trade USA, 2012). Very toxic chemicals are not to be used at all and are not necessary for all standard recyclebot-based operation. Although it should be pointed out that improper use of a recyclebot can cause combustion of the plastic and the concomitant toxic smoke. Further work is needed to quantify these hazards and should be shared with the global community. Chemicals are to be used safely and in accordance with published handling guidelines. Waste (e.g. non-recyclable pieces of plastic) is to be responsibly managed such as recycling conventionally. Procedures should be implemented to make efficient and rational use of water sources, which are necessary for the washing of the plastic containers as seen in Figure 2. Protection of soil, water and biodiversity is important and as such the ethical filament company should document its involvement in local and regional environmental projects related to supporting the biodiversity of the region (Fair Trade USA, 2012). Fair trade filament will be made out of plastic taken out of landfills and recycled into 3-D printer feedstock. It can then be used to make useful and often highly valuable products (Pearce, 2014). Care needs to be taken to ensure no plastic that may contain BPA is recycled into containers or utensils for holding or serving food (The National Toxicology Program, 2008). Plastics coded 3 and 7 may contain BPA and should not be used in these situations (National Institute for Environmental Health Sciences, 2013). This is problematic as PLA, which is the current 3-D printing filament of choice is labeled 7. It appears clear that future policy work should include a larger and more detailed plastic recycling code than is currently available in the U.S., which would benefit not only this specific application, but recycling of plastics in the general market.

The additional goals for this standard would include improving the thermal insulation on the recyclebots to improve thermal efficiency and undertaking and open-source publishing findings to develop filament additives that improve printability, bed adhesion, print speed, color fastness, mechanical toughness, etc. that are all non-toxic from renewable supplies. In addition, companies would both develop and publish methods to further reduce water use and methods for water recycling during the washing of the post-consumer plastic containers. The companies will also undertake research into open-source scientific hardware (Pearce, 2012; 2014) for characterizing the chemical composition of unknown plastic. For example, PLA, which is the recyclable and compostable premium commercial 3-D printing filament most used today, is grouped with "other" recycle code 7 plastics. If there was an easy inexpensive way to sort these valuable polymers out to be used in the recyclebot it would further help the entire industry. Finally, when possible the electricity used for the recyclebot operation should be from renewable and sustainable sources of energy. There has already been some technical development of solar-powered 3-D printers (King, et al., 2014) and further work could produce solar photovoltaic powered recyclebots. In addition, to the clear ecological benefit of offsetting the combustion of fossil fuels and their concomitant pollution, there is also the potential advantage of flexibility. For example, a solar-powered recyclebot has the potential to be transported by the waste pickers to any location, which is nearest a source of water for cleaning the plastic and the landfill. This could reduce both the transportation costs (energy and time) as well as reduce the overall environmental impact. Finally, the use of solar-powered RepRaps would enable the onsite production of valuable plastic products in any community, even those that are isolated in rural areas or in depressed sections of metropolitan areas that lack access to grid-tied electricity.

\subsection{Health and Safety Standards}

Employers must safeguard workers' rights under national and international labor and social security laws and regulations (FLA, 2013). Workplaces, machinery, equipment and worker transportation are equipped with adequate safety devices to help prevent accidents, and are safe. In this case the recyclebot has already had an open-source 3-D printable chain guard developed (Thingiverse, 2013). In addition, with the recent development of a RepRap capable of printing in steel (Anzalone, et al., 2014), it within near-term potential applications to develop a completely 3-D printable recyclebot and the possibility of a more robust device capable of fabricating metal filament. Because the recyclebot device is mostly metal, it is important to connect the body to ground, and preferably have the plug connected a socket that is protected by ground leak protection. The only significant danger then comes from the heater, which is insulated and placed so that it cannot cause combustion in the facilities used for the operation. The control electronics are all low voltage and therefore without risk. A maintenance and repair system is put in place to ensure a safe, clean and hygienic environment at all times. A written health and safety policy should be implemented and in areas where the workers are not literate, an image-based safety system should be used. The company ensures that Personal Protective Equipment is provided to workers appropriate to their tasks, free of charge, and that they are instructed and monitored in its proper use. The company has appointed a Medical Officer that maintains complete and updated records on workers' illnesses, accidents, first aid health care and other health care provided, and actions taken for improvements. Records are 
kept of all work accidents and related first aid response. The sanitary facilities are clean and hand washing facilities are next to the sanitary facilities. Potable drinking water is clearly labeled and easily accessible to all workers during their working period (Fair Trade USA, 2012).

Additional goals would include establishing a testing procedure and method of mitigating potentially harmful fumes from filament production. In addition, as companies mature they can appoint a medical officer to maintain the records and the health and safety equipment. Finally, setting up programs to sort the waste before it enters the dump increases the amount of waste being recycled as well as makes it safer and more sanitary for the workers as scavenging from open dumps is considered to be the most damaging to health (Wilson, Velis and Cheeseman, 2006).

\subsection{Social Standards}

Following protocols for other fair trade products, no person shall be discriminated against for hiring, compensation, advancement, discipline, termination or retirement, on the basis of gender, race, religion, age, disability, sexual orientation, nationality, political opinion, social group or ethnic origin. No physical, sexual, psychological or verbal harassment or abuse will be tolerated (FLA, 2013).

Employees have the right to establish or join an independent union, collectively bargain for better working conditions, elect their advisors and design their own programs (Fair Trade USA, 2012).

No form of corporal punishment is to be used. Wages may not be withheld as a disciplinary tool (Fair Trade USA, 2012).

\section{Discussion}

Creating a new market with a viable commodity (ethical 3-D printer filament) and organizing waste picker cooperatives and associations can also enhance the status of current waste scavengers. Instead of being considered little more than thieves, their work could be seen as more legitimate. Through proper marketing, they may start to be seen as environmentalists and entrepreneurs, leaders of recycling, turning trash into high-value items and additional economic development for their communities. They can then negotiate with the local authorities and/or the private sector and this legitimizes their activities. Government support for waste picker organizations has already shown the possibility of creating jobs and reducing poverty (Medina, 2008). When municipalities work directly with organizations they eliminate the need for middlemen, increasing pickers' income (Medina, 2000). In this instance, local governments could supply the relatively modest capital necessary for the recyclebot filament manufacturing infrastructure and facilities (e.g. water) for processing. The shorter supply chain will also result in lower end filament prices, since products are marked up every time they are bought by a middleman. A larger variety of environmentally conscious and affordable products will be made available to a growing number of ethically considerate consumers. This process can be significantly extended if policies are put in place to begin using more bio-based PLA in all packaging products for which the polymer is suitable. As PLA begins to become more popular in containers, more premium feedstock would be made available further improving the environmental footprint of the process. Again, this could be accelerated by improving the recycling code and creating policies to phase out less-easily recycled plastics.

Programs like the proposed ethical filament ecosystem are already working. Waste pickers working with city governments save money in waste pickup and recover much more material that can be recycled (Medina, 2008). The Kagad Kach Patra Kashtakari Panchayat group based in Pune, one of the first municipalities in India to authorize waste pickers to collect recyclables, is a trade union of over 8,000 organized waste pickers whose combined labor saved the municipality over US\$300,000 in municipal waste transport costs (WEIGO, 2012). Recovery rates as high as $80 \%$ are achieved by the Zabbaleen in Cairo due to intensive manual sorting and their expertise at extracting waste with value (Iskandar, 2003). Similar to already established coffee and other fair trade commodities, which require raw material to be harvest and transported out of the area, the ethical filament initiative will use waste produced by the area and turn it into a product that can be cycled back into the community or shipped out for a profit. With the addition of recyclebots the plastic they recycle can go directly into making new products (ethical filament) and with RepRaps, finished goods. In addition, as middlemen are not necessary, more of the profits can return to the pickers.

To assist in the growth of this model of waste plastic recycling two organizations have already been created: the Ethical Filament Foundation and the Plastic Bank. The Ethical Filament Foundation is a not for profit member-owned organization that has five core methods of providing assist this goal (Ethical Filament Foundation, 2014a): i) Create and brand an ethical filament production standard and a certification process; ii) Advertise and market the Ethical Filament standard and certification process; iii) Promote the concept of 
recycling to produce ethical 3-D printing filament that is sold to improve the livelihoods of waste pickers and their communities worldwide; iv) Sponsor research and development to improve the process for waste recycling at the grass roots level for use in 3-D printing; v) Release research to the public domain for use on an unrestricted basis by social benefit organizations. They are developing a standard based on the results of this paper (Ethical Filament Foundation, 2014b), which has both minimum and progress criteria. In addition, they are working with ProtoPrint in India to pilot their approach (Protoprint, 2014). Taking a slightly different approach, the Plastic Bank is a triple bottom line social enterprise that is turning plastic waste into a currency that can be exchanged to help lift people out of poverty and transition them into a better life (Plastic Bank, 2014). The Plastic Bank sets up exchange and recycling centers for post-consumer plastic waste in developing countries, while targeting areas with high amounts of poverty and plastic-related pollution. The plastic waste currency is exchanged for access to income, education and 3-D printing services to lift people out of poverty. The Plastic Bank is marketing their recycled plastic as "Social Plastic", which improves the life of a person in need while cleaning the planet. Their goal is to lead the movement towards global demand for the use of Social Plastic in everyday products in order to use the increased capital to provide higher rewards for the waste pickers (Plastic Bank, 2014). The work of the Ethical Filament Foundation, the Plastic Bank, their partners and others that are entering the market will all help drive poverty reduction and ecological impact minimization from waste plastic.

The analysis provided in this paper has shown that waste plastic recycling into 3-D printer filament is technically viable having been demonstrated by many research groups and successfully commercialized, that the growth of prosumer 3-D printing provides a market demand for filament and the existing market for socially responsible goods can provide a similar impetus for ethical, fair trade or social filament. Social enterprises already exist using this model and are expanding throughout many areas in the developing world. The possibility of waste recovery for use in 3-D printing is applicable everywhere there are people using plastic, which is most of the regions on Earth that humans inhabit. Combined with the substantial possibilities of 3-D printing and the exponential rate at which open-source designs are being created, the market for recycled ethical filament could extend to a significant fraction of the world population.

\section{Conclusions}

This paper has established a market opportunity for producing ethical 3-D printer filament from five converging trends: 1) the market for 3-D printers is expanding, 2) exponential growth in free open-source designs, 3) commercial filament is being sold large markups, 4) waste plastic extruders (recyclebots) have been developed, and 5) there is a growing concern and interest among consumers for ethically produced products. To meet the needs of this market opportunity, this paper then developed and discussed the basic guidelines for an "ethical product standard" for 3-D printing filament. These guidelines include i) minimum pricing, ii) the potential for and the application of a fair trade premium, iii) labor standards, iv) environmental standards, v) health and safety standards, and vi) social standards including those that cover discrimination, harassment, freedom of association, collective bargaining and discipline. These ethical filament standards provide a path to improved economic development for some of global societies most marginalized peoples, while improving the supply chain for 3-D printing materials.

\section{Acknowledgements}

The authors would like to acknowledge support from Tech for Trade and the Research and Engineering Apprenticeship Program (REAP). The authors would also like to acknowledge helpful discussions with W. Hoyle, S. Snabes and D. Gayle.

\section{References}

3Ders. (2013). Retrieved August 14, 2013, from http://www.3ders.org/pricecompare/

Adriani, F., \& Becchetti, L. (2002). Fair trade: a "third generation welfare" mechanism to make globalisation sustainable.

Ahmed, S. A., \& Ali, M. (2004). Partnerships for solid waste management in developing countries: Linking $\begin{array}{lllll}\text { theories to realities. } & \text { Habitat }\end{array}$ http://dx.doi.org/10.1016/S0197-3975(03)00044-4

Alibaba. (n. d.). Retrieved Septebmer 6, 2013, from http://www.alibaba.com/showroom/pla-resin.html

Anzalone, G. C., Glover, A. G., \& Pearce, J. M. (2013). Open-Source Colorimeter. Sensors, 13(4), 5338-5346. http://dx.doi.org/10.3390/s130405338

Anzalone, G. C., Zhang, C., Wijnen, B., Sanders, P. G., \& Pearce, J. M. (2014). Low-Cost Open-Source 3-D 
Metal Printing. IEEE Access, 1, 803-810. http://dx.doi.org/10.1109/ACCESS.2013.2293018

Bacon, C. (2005). Confronting the Coffee Crisis: Can Fair Trade, Organic, and Specialty Coffees Reduce Small-Scale Farmer Vulnerability in Northern Nicaragua? World Development, 33(3), 497-511. http://dx.doi.org/10.1016/j.worlddev.2004.10.002

Baechler, C., DeVuono, M., \& Pearce, J. M. (2013) Distributed Recycling of Waste Polymer into RepRap Feedstock. Rapid Prototyping Journal, 19(2), 118-125. http://dx.doi.org/10.1108/13552541311302978

Baradaran, S., \& Barclay, S. (2011). Fair Trade and Child Labor. Columbia Hum. Rts. L. Rev., 43, 1-63.

Becchetti, L. (2008). The Effects of Fair Trade on Affiliated Producers: An Impact Analysis on Kenyan Farmers. World Devlopment, 36(5), 823-842. http://dx.doi.org/10.1016/j.worlddev.2007.05.007

Bernache, G. (2003). The environmental impact of solid waste management: The case of Gaudalajara metro area. Resources Conservation and Recycling, 39(3), 223-237. http://dx.doi.org/10.1016/S0921-3449(03)00029-6

Bleijerveld, B. (2014). Plastics that can be recycled for 3-D printing. Retrieved July 4, 2014, from http://www.perpetualplasticproject.com/blog/2014/5/30/plastics-recycled-for-3dprinting

Blua, A. (2013). Radio Free Europe Radio Library "A New Industrial Revolution: The Brave New World Of $3 D$ Printing".

Retrieved

from http://www.rferl.org/content/printing-3d-new-industrial-revolution/24949765.html

Brenton, P., Edwards-Jones, G., \& Jensen, M. (2009). Carbon Labelling and Low Income Country Exports: An Issues Paper. Document Policy Review, 27(3), 243-267. http://dx.doi.org/10.1111/j.1467-7679.2009.00445.x

Chaturvedi, B. (1998). Public waste private enterprise. Heinrich Boel Stiftung, Berlin.

Douglass, C. (2013). The 3D Printing Extruder Reinvented - The Dual and Quad. Retrieved August 20, 2013, from http://www.kickstarter.com/projects/dglass3d/the-3d-printing-extruder-reinvented-the-dual-and-q

Ehrenberg, D. S. (1995). The Labor Link: Applying the International Trading System to Enforce Violations of Forced and Child Labor. Yale J. Int'1 L. 20;361.

Elmore, T. (2013). Filabuster: A robust, inexpensive filament extruder. Retrieved August 20, 2013, from http://www.kickstarter.com/projects/833191773/filastruder-a-robust-inexpensive-filament-extruder?ref=live

Ethical Filament Foundation. (2014a). Retrieved July 4, 2014, from http://www.ethicalfilament.org/why/

Ethical Filament Foundation. (2014b). Proposed structure for a fair trade standard for recycled filament. An Ethical Filament Standard for 3-D Printing. Retrieved July 4, 2014, from http://www.ethicalfilament.org/wp-content/uploads/2014/04/Fair-Trade-Standards-for-Filament-Paper.pdf

EWE Industries. (2014). EWE. Retrieved July 4, 2014, from http://www.eweindustries.com/

Fair Trade Certified. (2013). Fair Trade Coffee. Retrieved August 20, 2013, from http://www.groundsforchange.com/learn/fairtrade.php

Fair Trade USA. (2012). Fair Trade USA: Farm Workers Standard: Version1.1. PDF. Retrieved August 16, 2013, from http://filabot.com

Fair Trade USA. (2013). Key Principles: Fair Trade Standards. Retrieved August 16, 2013, from http://fairtradeusa.org/certification/standards

Fairtrade Foundation. (2013a). The Fairtrade premium. Retrieved August 16, 2013, from http://www.fairtrade.org.uk/what_is_fairtrade/fairtrade_certification_and_the_fairtrade_mark/the_fairtrade_ premium.aspx

Fairtrade Foundation. (2013b). Why is Fairtrade unique? Retrieved August 16, 2013, from $\mathrm{http}: / /$ www.fairtrade.org.uk/what_is_fairtrade/fairtrade_is_unique.aspx

FLA. (2013). Labor Standards: FLA Workplace Code of Conduct. Retrieved August 16, 2013, from http://www.fairlabor.org/labor-standards

Hilowitz, J. (1997). Social Labelling to Combat Child Labour: Some Considerations. Int'l Lab. Rev., 136, 215.

ILO. (2013). What is child labour. Retrieved August 16, 2013, from http://www.ilo.org/ipec/facts/lang--en/index.htm

Iskandar, L. K. (2003). Integrating local community-based waste management into international contracting. In proceedings of solid waste collection that benefits the urban poor, 9-14 March, Dar Es Salaam, Tanzania. 
Switzerland: The SKAT Foundation.

Jaffee, D. (2007). Brewing Justice: Fair Trade Coffee, Sustainability, and Survival. Berkeley, CA: University of California Press.

Jones, R., Haufe, P., Sells, E., Iravani, P., Olliver, V., Palmer, C., \& Bowyer, A. (2011). RepRap - the replicating rapid prototyper. Robotica, 29(1), 177-191. http://dx.doi.org/10.1017/S026357471000069X

King, D. L., Babasola, A., Rozario, J., \& Pearce, J. M. (2014). Development of Mobile Solar Photovoltaic Powered Open-source 3-D Printers for Distributed Customized Manufacturing in Off-grid Communities. Challenges in Sustainability (in press).

Kreiger, M., \& Pearce, J. M. (2013a). Environmental Life Cycle Analysis of Distributed 3-D Printing and Conventional Manufacturing of Polymer Products. ACS Sustainable Chemistry \& Engineering, 1(12), 1511-1519. http://dx.doi.org/10.1021/sc400093k

Kreiger, M., \& Pearce, J. M. (2013b). Environmental Impacts of Distributed Manufacturing from 3-D Printing of Polymer Components and Products. MRS Online Proceedings Library, 1492.

Kreiger, M., Anzalone, G. C., Mulder, M. L., Glover, A., \& Pearce, J. M. (2013). Distributed Recycling of Post-Consumer Plastic Waste in Rural Areas. MRS Online Proceedings Library, 1492.

Kreiger, M., Mulder, M. L., Glover, A. G., \& Pearce, J. M. (2014). Life Cycle Analysis of Distributed Recycling of Post-consumer High Density Polyethylene for 3-D Printing Filament. Journal of Cleaner Production, 70, 90-96. http://dx.doi.org/10.1016/j.jclepro.2014.02.009

Litvinoff, M., \& Madeley, J. (2007). 50 Reasons to Buy Fair Trade. London, England: Pluto Press.

Loureiro, M. L., McCluskey, J. J., \& Mittelhammer, R. C. (2001). Assessing Consumer Preferences for Organic, Eco-labeled, and Regular Apples. Journal of Agricultural and Resource Economics, 26(2), 404-416.

Low, W., \& Davenport, E. (2005). Postcards from the edge: maintaining the 'alternative' character of fair trade. Sustainable Development, 13(3), 143-153. http://dx.doi.org/10.1002/sd.275

Lyman Filament Extruder. WWW document. (http://www.thingiverse.com/thing:30642).

Make. (2013). Make: ultimate guide to $3 D$ printing. Winter. Oreilly.

Marcovitz, H. (2011). Fair Trade. Edina, MN: ABDO Publishing Company.

Martens, T., Mears, L., Dotson, M., Graham, M., \& Sanger, P. (2011). Use of Fused Deposition Modeling of Polyphenylsulfone for Centrifugal Casting of Polyurethane: Material, Surface, and Process Considerations J. Manuf. Sci. E. 133(5), 051003.

McDonagh, P. (2002). Communicative campaigns to effect anti-slavery and fair trade: The cases of Rugmark and $\begin{array}{llll}\text { Cafédirect. European Journal of } & \text { 642-666. }\end{array}$ http://dx.doi.org/10.1108/03090560210422925

McMurty, J. J. (2009) Ethical Value-Added: Fair Trade and the Case of Café Femenino. Journal of Business Ethics, 86(1), 27-49. http://dx.doi.org/10.1007/s10551-008-9760-x

Medina, M. (2000). Scavenger cooperatives in Asia and Latin America. Resources, Conservation and Recycling, 31(1), 51-69. http://dx.doi.org/10.1016/S0921-3449(00)00071-9

Medina, M. (2008). The Informal recycling Sector in Developing Countries: Organizing Waste Pickers to Enhance their Impact. World Bank, Washington, DC.

National Institute for Environmental Health Sciences. (2013). Bisphenol A (BPA). Retrieved August 20, 2013, from http://www.niehs.nih.gov/health/topics/agents/sya-bpa/

National Toxicology Program, The. (2008). The National Toxicology Program (NTP) Brief On Bisphenol A (BPA) PDF. Retrieved August 20, 2013, from http://www.niehs.nih.gov/health/topics/agents/sya-bpa/

Nicholls, A., \& Opal, C. (2004). Fair Trade: Market-Driven Ethical Consumption. London, England: SAGE Publications Ltd.

Omni Dynamics. (2014). Strooder. Retrieved July 4, 2014, from http://omnidynamics.co.uk/shop/strooder

Pearce, J. M. (2012a). Building Research Equipment with Free, Open-Source Hardware. Science, 337(6100), 1303-1304. http://dx.doi.org/10.1126/science.1228183

Pearce, J. M. (2012b). The Case for Open Source Appropriate Technology. Environment, Development and 
Sustainability, 14, 425-431. http://dx.doi.org/10.1007/s10668-012-9337-9

Pearce, J. M. (2014). Open-Source Lab: How to Build Your Own Hardware and Reduce Research Costs. Elsevier.

Pearce, J. M., Morris Blair, C., Laciak, K. J., Andrews, R., Nosrat, A., \& Zelenika-Zovko, I. (2010). 3-D Printing of Open Source Appropriate Technologies for Self-Directed Sustainable Development, Journal of Sustainable Development, 3(4), 17-29. http://dx.doi.org/10.5539/jsd.v3n4p17

Perpetual Plastic Project. (2014). Perpetual Plastic Project. Retrieved July 4, 2014, from http://www.perpetualplasticproject.com/

Plastic Bank. (2014). Plastic Bank. Retrieved July 4, 2014, from http://plasticbank.org/

Protoprint. (2014). The World's First Fair Trade Filament. Retrieved July 4, 2014, from http://www.protoprint.in/

Raynolds, L. T., \& Ngcwangu, S. U. (2010). Fair Trade Rooibos tea: Connecting South African producers and American consumer markets. Geoform, 41(1), 74-83. http://dx.doi.org/10.1016/j.geoforum.2009.02.004

Sahota, A., Haumann, B., Givens, H., \& Baldwin, C. (2008). Ecolabelling and Consumer Interest in Sustainable Products. In C. Baldwin (Ed.), Sustainability in the Food Industry. Ames, IA: Wiley-Blackwell.

Salahuddin, K., \& Shamim, I. (1992). Women in urban informal sector: Employment pattern, activity types and problems. In Women for Women (Vol. 18, pp. 4-5). Dhaka, Bangladesh.

Shreck, A. (2005). Resistance, redistribution, and power in the Fair Trade banana initiative. Agriculture and Human Values, 22(1), 17-29. http://dx.doi.org/10.1007/s10460-004-7227-y

The Economist. (2012). A Third industrial Revolution. The Economist.

Thingiverse. (2013). RecycleBot Chain Guard. Retrieved from http://www.thingiverse.com/thing:122258

Thingiverse. (2014). Retrieved July 4, 2014, from http://www.thingiverse.com/

Thompson, C. (2012). Open Source Universal 3D Printer Extruder (Dual Extrusion). Retrieved August 16, 2013, from

$\mathrm{http} / / /$ www.kickstarter.com/projects/qu-bd/open-source-universal-3d-printer-extruder-dual-ext?ref=search

WIEGO. (2012). Integrating Waste Pickers into Municipal Solid Waste Management in Pune, India. WIEGO Policy Brief (Urban Policies) No 8.

Wilson, D. C., Velis, C., \& Cheeseman, C. (2006). Role of informal sector recycling in waste management in $\begin{array}{llll}\text { developing } & \text { countries. } & \text { Habitat } & \text { International, }\end{array}$ http://dx.doi.org/10.1016/j.habitatint.2005.09.005

Wittbrodt, B. T., Glover, A. G., Laureto, J., Anzalone, G. C., Oppliger, D., Irwin, J. L., \& Pearce, J. M. (2013). Life-cycle economic analysis of distributed manufacturing with open-source 3-D printers. Mechatronics, 23, 713-726. http://dx.doi.org/10.1016/j.mechatronics.2013.06.002

Zhang, C., Anzalone, N. C., Faria, R. P., \& Pearce, J. M. (2013). Open-Source 3D-Printable Optics Equipment. PLoS ONE, 8(3), e59840. http://dx.doi.org/10.1371/journal.pone.0059840

\section{Copyrights}

Copyright for this article is retained by the author(s), with first publication rights granted to the journal.

This is an open-access article distributed under the terms and conditions of the Creative Commons Attribution license (http://creativecommons.org/licenses/by/3.0/). 